\title{
Article \\ Exploration of Critical Success Factors of Logistics 4.0: A DEMATEL Approach
}

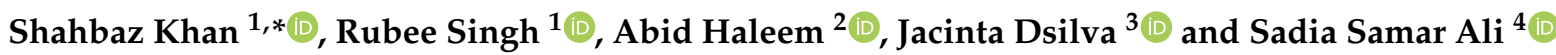 \\ 1 Institute of Business Management, GLA University, Mathura 281406, India; dr.rubeerajput@gmail.com \\ 2 Department of Mechanical Engineering, Jamia Millia Islamia, New Delhi 116458, India; ahaleem@jmi.ac.in \\ 3 School of Business, University of Balamand, Balamand 116458, Lebanon; jacinta.dsilva@fty.uobd.ac.ae \\ 4 Department of Industrial Engineering, Faculty of Engineering, King Abdul-Aziz University, \\ Jeddah 21589, Saudi Arabia; ssaali@kau.edu.sa \\ * Correspondence: shahbaz.me12@gmail.com
}

Citation: Khan, S.; Singh, R.; Haleem, A.; Dsilva, J.; Ali, S.S. Exploration of Critical Success Factors of Logistics 4.0: A DEMATEL Approach. Logistics 2022, 6, 13. https://doi.org/ 10.3390/logistics6010013

Academic Editor: Robert Handfield

Received: 28 December 2021

Accepted: 25 January 2022

Published: 6 February 2022

Publisher's Note: MDPI stays neutral with regard to jurisdictional claims in published maps and institutional affiliations.

Copyright: (C) 2022 by the authors. Licensee MDPI, Basel, Switzerland. This article is an open access article distributed under the terms and conditions of the Creative Commons Attribution (CC BY) license (https:// creativecommons.org/licenses/by/ $4.0 /)$.

\begin{abstract}
Background: Fourth Industrial Revolution (Industry 4.0) has revolutionized the operations, technologies, logistics and supply chain. To align with industry 4.0, the conventional logistics processes need to upgrade into digital logistics (logistics 4.0). This study aims to analyse the critical success factors of logistics 4.0. Methods: To accomplish this objective a comprehensive literature review is conducted for the identification of the critical success factors of logistics 4.0 with the expert's input. These critical success factors are interrelated, and this interrelationship is explored through the DEMATEL approach. The applied methodology is categorised the critical success factors into cause-and-effect groups. Six factors belong to the cause group and the remaining four belong to the effect group. Results: The 'top management commitment and support', 'aligning the initiatives of logistic 4.0 with organizational strategy' and 'technological infrastructure' are the most influential critical success factors. This analysis also recognized the most influential and influenced factor amongst all identified critical success factors that will help the practitioners to optimal utilization of the resources. Conclusions: The findings of the study support the managers and practitioners in strategizing their effort for logistics 4.0 adoption.
\end{abstract}

Keywords: critical success factors; DEMATEL; digital manufacturing; Industry 4.0; logistics 4.0

\section{Introduction}

Professionals, managers, and government officials are increasingly interested in Industry 4.0 since its effective execution will result in competitive benefits for businesses and state economies [1-3]. Industry 4.0 began in Germany to encourage the development of manufacturing $[4,5]$. Other nations have adopted this paradigm, such as the United States adopted the "Smart Manufacturing", China focusing on "Made in China 2025", the UK popularised the "Future of Manufacturing", India launched the "Smart Advanced Manufacturing and Rapid Transformation Hub (SAMARTH)- Udyog Bharat 4.0", etc. [6,7]. The aim of Industry 4.0 is to create intelligent companies and supply chains using cutting-edge technologies including cyber-physical systems (CPS), analytics, big data, and the Internet of Things (IoT) $[7,8]$. These technologies are used to upgrade the different elements of the supply chain, such as logistics, manufacturing, and warehousing to the next level. Among these components, logistics 4.0 is considered as an essential component of Industry 4.0, and adoption of logistics 4.0 might be beneficial for the digitalisation of the supply chain.

Logistics 4.0 is defined by some authors as a new paradigm that is interlinked with Industry 4.0. For instance, Jeschke [9] conceptualized logistics 4.0 from short term and medium-term approaches. From the short-term perspective, logistics 4.0 is defined as "... firm and mutually related processes between independent members with the use of large amounts of data". From the medium-term perspective, "... as autonomous, self-organizing systems within other systems". This definition focused on the subsystems 
of the logistics that are equipped with smart technologies such as smart sensors, big data, IoT, cyber-physical systems, etc. These technologies develop ecosystems that are highly data-driven and fulfil the customized demand of the customer more effectively. Similar to this, Timm and Lorig $[10,11]$ also define logistics 4.0 “ $\ldots$ as a logistic system which consists of independent subsystems and behaviour of these subsystems depends on other surrounding subsystems".

Further, Wang [12] proposed a very comprehensive definition of logistics 4.0 as " . . a collective term for technologies and concepts of value chain organization. Within the logistics, CPS monitor physical processes, create a virtual copy of the physical world and make decentralized decisions. Over the IoT, CPS communicate with machines and humans in real-time. Data mining discovers knowledge to support the decision-making process. Via the IoS, both internal and cross-organizational services are offered and utilized by participants of the value chain".

Therefore, logistics 4.0 refers to the integration of logistics with smart technologies to meet the demand for highly customized products and services. These advanced technology adoptions require higher motivation and financial investment to implement logistics 4.0. Due to the high technological cost, high cost of infrastructure, the complex supply chain network, global participation and security and privacy concerns, this transformation is challenging $[13,14]$.

Logistics 4.0 is also characterized by implementation challenges that require consideration from industries and academia. These issues need the investigation of Critical Success Factors (CSFs) that might be crucial for the adoption of logistics 4.0. The transformation of conventional logistics into logistics 4.0 depends on several factors that are significant for the organisations. Therefore, it is necessary to identify these CSFs of the logistics 4.0 adoption for smooth and effective adoption. Furthermore, managers should understand the structural interdependencies among the selected CSFs to efficient and effective management. As a result, this study is being carried out to accomplish these requirements. To fill these research gaps and assist policymakers for efficient adoption of logistics 4.0, this study offers the following research objectives:

- To identify the major CSFs of adoption of logistics 4.0;

- To develop causal relationships among the finalised CSFs to facilitate logistics 4.0;

- To prioritise the CSFs as per their cause-and-effect score.

To achieve the aforementioned study objectives, we have identified CSFs by a comprehensive review of literature, which was followed by feedback from experts. After finalisation of the CSFs, we used the Decision-Making Trial and Evaluation Laboratory (DEMATEL) to investigate causal interrelationships between the finalised CSFs.

The study is structured as follows: Section 2 provide a brief overview of logistic 4.0 related studies. Section 3 deals with the adopted research methodology. The data analysis is conducted in Section 4. The results are discussed in Section 5. The implications of this study are discussed in Section 6, followed by the conclusion in Section 7.

\section{Literature Review}

Literature suggests that logistics 4.0 initiatives benefit the economy by lowering logistics costs (such as labour costs), increasing productivity and efficiency, improving customer satisfaction through reduced lead time, and improving information accuracy and responsiveness $[15,16]$. The implementation aspect of the logistics 4.0 studies is rarely found in the literature. Most of the studies are focused on the technological aspect of logistics 4.0 and how these technologies are beneficial for the adoption of logistics 4.0. For instance, Atzeni et al. [17] studied that robots are playing a vital role in logistics, which can help in picking, operations, and spreading awareness of logistics in Industry 4.0. They proposed the concept of collaborative robots is called Cobots, which can be applied in the smart logistics system. Markov and Vitliemov [18] studied the implementation of blockchain technologies on logistics and supply chains in the context of the automotive industry. They further claimed that blockchain technologies create huge value to logistics 
4.0. In this research, they identified possible opportunities of logistics 4.0 and supply chain 4.0 for developing sustainable logistics and supply chains [19].

Winkelhaus and Grosse [20] reviewed and purposed a framework for logistics 4.0. They further explore how this framework can be applied for the identification of future strategies of logistics and technologies to fulfil sustainable logistics operations. They also develop new technological solutions, such as the IoT, CPS, big data, and mobile-based systems, for meeting the current and future demands. In this row, Kucukaltan et al. [21] studied how practitioners are adopting a multidimensional approach for the projections and their reflections of Industry 4.0 in logistics. It can be influenced as a result of the development of industries in which changes can be seen from the operational, financial, and human resources aspects.

Some studies show that the impact of logistics is 4.0 on firm performance [22,23]. Torbacki and Kijewska [24] studied the performance parameters of logistics along with the production processes that could be used in logistics 4.0 for achieving sustainability. It also focused on performance indicators of both logistics as well as manufacturing processes, which can be helpful to measure the firm performance. Further, Nantee and Sureeyatanapas [23] focused on how to understand and implement the impact of logistics 4.0 initiatives such as automated warehousing systems on sustainability performance in different companies. Kodym et al. [25] argued that digital transformation in logistics and cooperative systems could make the supply chain smarter, more efficient, and more transparent in every stage of logistics and manufacturing. They highlighted how practitioners can use smart technologies such as blockchain, IoT, big data, data mining, CPS to identify the risks associated with logistics 4.0. Bag et al. [26] highlight the effect of logistics 4.0 capabilities on companies' performance in three areas, namely, technological, organizational, and environmental. Among them, environmental capabilities can help to reduce maintenance costs through planning and scheduling. Further, sustainable communication and visibility in the logistics 4.0 process can improve the manufacturing operation of companies.

The impact of the Industry 4.0 technologies on logistics operations are also assessed by some authors [8,27-29]. These technologies are improving logistics processes by reducing waste through the integration of the lean 4.0 concept. Beier et al. [30] explain that Industry 4.0 is not a technology-based concept only, it is rather a technological amalgamation of social and organizational contexts. They further argue that the concept has failed to accomplish the societal and sustainable benefits in its initial implementation. However, Wagner et al. [27] recommended that the first estimation in Industry 4.0 can be achieved by employing a lean production system especially when a cyber-physical-based Just-inTime (JIT) approach is used. Mayr et al. [28] used a case-based method to have the costeffectiveness by using cloud computing in TPM (Total Productive Maintenance) as lean 4.0 integration for the production of the electric drive. Rosin et al. [31], on the other hand, recommend that Industry 4.0 works well with Just-in-Time (JIT) and Jidoka. According to them, the most suggested technologies for the amalgamation of lean 4.0 with Industry 4.0 is IoT and simulation. A cluster equipped with the knowledge base, expertise in IT solutions, robotics and automation is needed for such integration [32].

Louis [33] has proposed Industry 4.0's dimensions, including automation of the production process, use of configurable equipment, integration of product development with physical and digital production, use of advanced analytics, innovative business models based on servitisation, and use of data for smart product delivery. A framework to relate the Industry 4.0 and World Class Manufacturing (WCM) concepts in the form of the WCMI4.0 matrix has also been proposed by D'Orazio et al. [34]. They also prepared a list of commonly used hundred Industry 4.0 technologies to be integrated with digital processes. Qin et al. [35] focus on the improvement of Industry 4.0 in manufacturing-based production systems. They propose a categorical framework built upon the levels of intelligence classifying as control, integration and intelligence levels. Tools used for each level are ranging from computer numeric controlling, programmable logic control having the IoT and CPS as the technological integration. Forchungs union's report [36] aims to create an 
eco-system by the technological existence, economic potential, skills, performance to have horizontal, vertical and end to end integration.

\section{Methodology}

To achieve the aforesaid objectives, a three-phase framework is proposed and the same is highlighted in Figure 1. In the first phase, a review of academic journals is conducted to identify the primary CSFs for the adoption of logistics 4.0. The article for the identification of CSFs is selected from the Scopus database. After the initial identification of the CSFs, a subject matter expert team provides the feedback for the finalisation of the CSFs of logistics 4.0 .

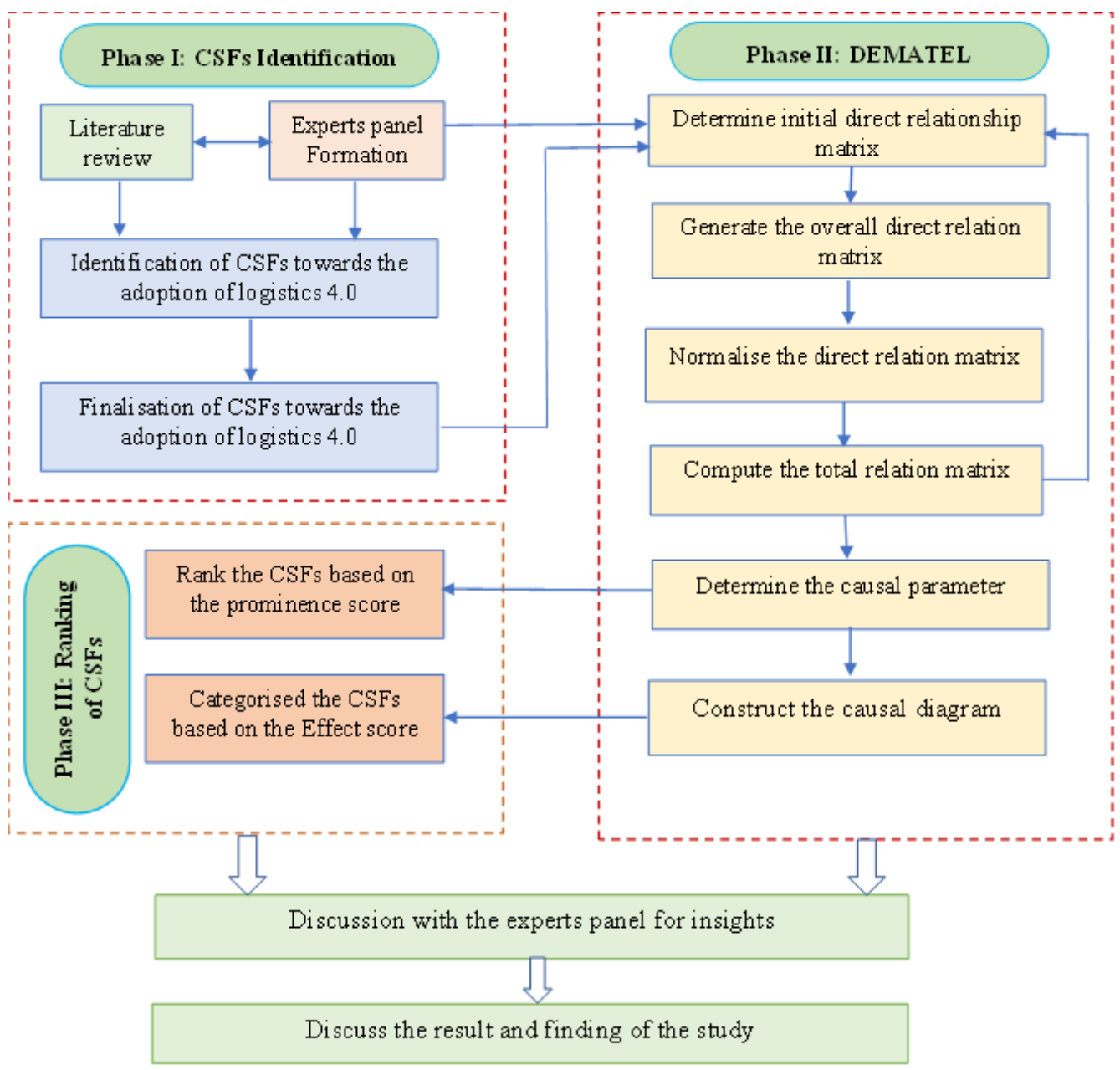

Figure 1. Research framework for this study.

In the second phase, the causal interrelationship is developed between the finalised CSFs. In order to develop the causal relationship, several methods are available in the literature such as Interpretive Structural Modelling (ISM), Total Interpretive Structural Modelling (TISM), WING, DEMATEL, etc. [37]. ISM and TISM have certain limitations, such as they only provide qualitative assessment rather than quantitative [38,39]. While DEMATEL can quantify the strength of interrelationship among the CSFs [40]. Therefore, the causal interrelationship between the finalised CSFs is evaluated using the DEMATEL method. In the third phase of the study, these CSFs are ranked based on their importance and dominance power. Further, the results of the analysis are discussed with the experts to gain deeper insights and get the recommendation to focus on the significant CSFs. 


\section{DEMATEL}

In 1976, DEMATEL was introduced as a method for evaluating the causal relationship between the factors [41]. It has now been widely employed in a variety of fields, including supply chain management, traceability, smart cities, healthcare, consumer behaviour, and many more $[42,43]$. The steps of the DEMATEL method are provided as follows:

Step I: Develop the direct influence matrix

An expert panel was constituted for this study, and their opinions were used to build the direct influence matrix. The experts use a questionnaire to measure the effect of one CSFs over others. As indicated in Table 1, the impact of a CSF ' $i$ ' over ' $j$ ' has been represented by kth expert using an 0-4 scale (0-no influence and 4-extremely high influence).

Table 1. Linguistic scale for influential score.

\begin{tabular}{cc}
\hline Scale & Influence Itensity \\
\hline 0 & No \\
1 & Low \\
2 & Moderate \\
3 & High \\
4 & Very High \\
\hline
\end{tabular}

The ' $x_{i j}$ ' denotes the impact of CSF ' $i$ ' on CSF ' $j$ ' and the diagonal element is 0 in the direct relationship matrix. An $n \times n$ matrix is generated for each respondent using the formula $X_{h}=\left[x_{i j h}\right]$, where ' $h$ ' denotes the $h$ th expert $(1 \leq h \leq k)$. As a result, ' $k$ ' experts provide ' $k$ ' matrices as $X_{1}, X_{2}, X_{3} \ldots X_{k}$.

Step II: Create an overall direct-relation matrix

Using input from $\mathrm{H}$ experts, create an overall direct-relation matrix, then use Equation (1) to get the average matrix $\mathrm{A}=\left[a_{i j}\right]$ :

$$
a_{i j}=\frac{\sum_{h=1}^{k} x_{i j}^{h}}{k}
$$

Step III: Develop the normalized initial direct-relation matrix

Create a normalized initial direct-relation matrix using the Equations (2) and (3):

$$
D=A S
$$

$$
\text { Where } S=\frac{1}{\max _{1 \leq i \leq n} \sum_{j=1}^{n} a_{i j}}
$$

Step IV: Compute the total relation matrix

Develop the total relation matrix " $T$ " using Equation (4):

$$
T=D \cdot(I-D)^{-1}
$$

where, "I" represents identity matrix.

Step V: Determine the causal parameters

Calculate the causal parameters with Equations (5) and (6):

$$
\begin{aligned}
& R_{i}=\sum_{j=1}^{n} t_{i j} \text { for all } i \\
& C_{j}=\sum_{i=1}^{n} t_{i j} \text { for all } j
\end{aligned}
$$

where $R_{i}$ signifies the row-wise summation and $C_{j}$ implies the column-wise summation. 
Step VI: Determine the Prominence and effect score

Prominence and effect score is calculated from Equations (7) and (8):

$$
\begin{aligned}
& P_{i}=R_{i}+C_{i} \\
& E_{i}=R_{i}-C_{i}
\end{aligned}
$$

The prominence score $\left(P_{i}\right)$ indicates how much net influence 'CSF $i$ ' adds to the system, while the impact score $\left(E_{i}\right)$ indicates how much net influence 'CSF $i$ ' subtracts from the system. The 'CSF $i$ ' creates a net cause if the effect score $\left(E_{i}=R_{i}-C_{i}\right)$ is greater than zero; otherwise, it produces a net effect. The prominence score is plotted on the $x$-axis and the effect score on the y-axis to create the causal diagram.

\section{Data Analysis}

\subsection{Identification of the CSFs of Logistics 4.0 Adoption}

The initial CSFs are identified through the literature review of the relevant articles. The Scopus database is used for the article selection, as it is considered the largest database of scientific peer-reviewed journals. The initial list of relevant keywords such as "logistic 4.0", "smart logistics", "digital logistics", and "critical success factors" are identified. Further, the combination (using a Boolean operator) of these keywords is searched for the article selection. After finalizing the article, a comprehensive review is conducted to prepare the initial list of CSFs towards the adoption of logistics 4.0. After that, an experts panel is formed that consists of six members, four from industry and two from academia. These experts are having enough knowledge about logistics 4.0 and related activities. The section of the experts is based on their experience in the field of logistics. The participated experts have more than eight-year work experience at the managerial level in the logistics company. These experts are working in established organisations that are doing logistics operations for more than 18 years and had minimum employee strength of 200. Initially, 17 logistics providers were selected for conducting the research, out of which only nine have expressed willingness to participate. Among the nine organisations, four experts are available to participate in the study and the remaining five are not available due to their time constraints. Two academic experts have also participated in this study that is working in the area of Industry 4.0 and logistics 4.0 and has enough knowledge about the logistics 4.0 operations. The details of the experts are provided in Table 2.

\begin{tabular}{|c|c|c|c|c|c|c|c|c|}
\hline S No & Designation & $\begin{array}{l}\text { Experience in } \\
\text { the Logistics } \\
\text { Industry } \\
\text { (in Years) }\end{array}$ & $\begin{array}{c}\text { Total } \\
\text { Experience } \\
\text { (in Years) }\end{array}$ & Gender & Education & $\begin{array}{c}\text { Size of } \\
\text { Organisation }\end{array}$ & $\begin{array}{l}\text { Nature of } \\
\text { Work/ } \\
\text { Country }\end{array}$ & Expertise Area \\
\hline 1. & $\begin{array}{l}\text { Managing } \\
\text { Director }\end{array}$ & 22 & 28 & Male & $\begin{array}{c}\text { Master of } \\
\text { Engineering }\end{array}$ & Medium & National & $\begin{array}{l}\text { Supply chain and } \\
\text { logistics management }\end{array}$ \\
\hline 2. & $\begin{array}{l}\text { Supply Chain } \\
\text { Manager }\end{array}$ & 17 & 23 & Male & $\begin{array}{l}\text { Master of } \\
\text { Engineering }\end{array}$ & Large & Multi-national & $\begin{array}{l}\text { Supply chain } \\
\text { management }\end{array}$ \\
\hline 3. & Logistics Head & 16 & 21 & Male & $\begin{array}{c}\text { Master of } \\
\text { Engineering }\end{array}$ & Large & Multi-national & $\begin{array}{c}\text { Logistics } \\
\text { management }\end{array}$ \\
\hline 4. & $\begin{array}{l}\text { Warehouse } \\
\text { Manager }\end{array}$ & 08 & 12 & Female & MBA & Small & National & $\begin{array}{c}\text { Logistics } \\
\text { Management, Smart } \\
\text { warehouse } \\
\text { development }\end{array}$ \\
\hline 5. & Professor & NA & 32 & Male & $\mathrm{PhD}$ & NA & India & $\begin{array}{c}\text { Industry } 4.0, \text { Logistics } \\
4.0 \text { and supply chain } \\
\text { Analytics }\end{array}$ \\
\hline 6. & $\begin{array}{l}\text { Associate } \\
\text { Professor }\end{array}$ & NA & 13 & Female & $\mathrm{PhD}$ & NA & UAE & $\begin{array}{c}\text { Logistics } \\
\text { Management }\end{array}$ \\
\hline
\end{tabular}

Table 2. Details of the participated experts.

After expert panel formation, the identified CSFs list that contains fourteen factors is put in front of the expert panel for their feedback. They have suggested dropping the two 
factors that are not relevant and merging the four factors into two. In this manner, ten CSFs are finalized, and the same are shown in Table 3.

Table 3. CSFs of logistics 4.0 adoption.

\begin{tabular}{|c|c|c|c|c|}
\hline S. No & CSFs & Code & Description & References \\
\hline 1. & $\begin{array}{l}\text { Technological } \\
\text { Infrastructure }\end{array}$ & CSF 1 & $\begin{array}{c}\text { Logistics } 4.0 \text { requires advanced technological } \\
\text { infrastructures such as IoT, big data and } \\
\text { cyber-physical systems to fulfil the demand of } \\
\text { Industry } 4.0\end{array}$ & [44-46] \\
\hline 2. & Trust and collaboration & CSF 2 & $\begin{array}{c}\text { Organizational and inter-organisational factors } \\
\text { such as operational effectiveness, collaboration, } \\
\text { and trust among the logistic partners for the } \\
\text { realisation of logistics } 4.0 \text {. }\end{array}$ & {$[26,47,48]$} \\
\hline 3. & Knowledge Transfer & CSF 3 & $\begin{array}{l}\text { Established the training program and modules to } \\
\text { create an environment of continuous learning and } \\
\text { training in the organisation. They allow easy } \\
\text { transfer of knowledge thus motivating the } \\
\text { organisation to adopt logistics } 4.0 .\end{array}$ & {$[21,29,49]$} \\
\hline 4. & $\begin{array}{c}\text { Development of } \\
\text { analytical capabilities }\end{array}$ & CSF 4 & $\begin{array}{c}\text { The success of logistics } 4.0 \text { depends on the data } \\
\text { analytics, and this involves a well-established } \\
\text { analytical capability }\end{array}$ & {$[21,23]$} \\
\hline 5. & $\begin{array}{l}\text { Smart work } \\
\text { environment }\end{array}$ & CSF 5 & $\begin{array}{c}\text { Employees need to work in a smart environment } \\
\text { because of the deployment of logistics } 4.0 \text {, which } \\
\text { includes new job descriptions, roles, and } \\
\text { responsibilities. }\end{array}$ & {$[8,50]$} \\
\hline 6. & $\begin{array}{l}\text { Aligning the initiatives } \\
\text { of logistic } 4.0 \text { with } \\
\text { organizational strategy }\end{array}$ & CSF 6 & $\begin{array}{l}\text { The adoption of logistics } 4.0 \text { is achieved through } \\
\text { the several logistics } 4.0 \text { initiatives and these } \\
\text { initiatives should be linked with organisational } \\
\text { strategies for better coordination. }\end{array}$ & {$[51,52]$} \\
\hline 7. & $\begin{array}{l}\text { Top management } \\
\text { commitment and } \\
\text { support }\end{array}$ & CSF 7 & $\begin{array}{l}\text { The adoption of any practice in an organisation } \\
\text { requires top management commitment and } \\
\text { support, and logistics } 4.0 \text { is no exception. }\end{array}$ & {$[53,54]$} \\
\hline 8. & Research environment & CSF 8 & $\begin{array}{c}\text { Logistics } 4.0 \text { is a relatively new concept that is } \\
\text { based on the latest technology, and it requires } \\
\text { extensive research. }\end{array}$ & [55] \\
\hline 9. & $\begin{array}{l}\text { Willingness to invest in } \\
\text { logistics } 4.0\end{array}$ & CSF 9 & $\begin{array}{c}\text { Risk aversion, or the fear of investing in innovative } \\
\text { solutions like logistics } 4.0 \text {, is a significant factor in } \\
\text { their adoption. }\end{array}$ & Expert's input \\
\hline 10. & Training and Education & CSF 10 & $\begin{array}{l}\text { Analytical and technical skills are necessary to } \\
\text { execute logistics } 4.0 \text { that requires training in the } \\
\text { form of seminars and workshops. }\end{array}$ & {$[56,57]$} \\
\hline
\end{tabular}

\subsection{DEMATEL Analysis}

The causal relationship is developed between the CSFs of adoption of logistics 4.0 using DEMATEL. In this study, only six experts have participated since the DEMATEL method can be applied with a reduced sample size [58]. Earlier studies advocate that the DEMATEL method could be applied with the inputs from five or fewer experts [59-64]. Therefore, the six experts are sufficient to apply the DEMATEL method and draw the conclusion from the obtained result. For a better understanding of the methodology, we have provided a brief overview of the DEMATEL to the experts. After that, experts were asked to provide the influence of one CSFs to others using the five-point linguistic scale through a direct-relation matrix. Six initial relationship matrices are generated in this way. These matrices are converted into an overall direct relationship matrix using Equation (1) and shown in Table 4. 
Table 4. The overall direct relationship matrix (A).

\begin{tabular}{ccccccccccc}
\hline CSFs & CSF 1 & CSF 2 & CSF 3 & CSF 4 & CSF 5 & CSF 6 & CSF 7 & CSF 8 & CSF 9 & CSF 10 \\
\hline CSF 1 & 0.000 & 2.500 & 2.833 & 3.833 & 3.167 & 3.000 & 1.333 & 3.000 & 4.000 & 3.667 \\
CSF 2 & 2.000 & 0.000 & 3.500 & 2.833 & 2.167 & 2.000 & 2.000 & 3.667 & 2.000 & 3.000 \\
CSF 3 & 2.000 & 2.667 & 0.000 & 4.000 & 3.000 & 3.000 & 2.167 & 3.000 & 1.000 & 2.000 \\
CSF 4 & 1.000 & 2.000 & 2.333 & 0.000 & 1.833 & 1.000 & 2.000 & 3.000 & 2.000 & 1.000 \\
CSF 5 & 2.000 & 2.167 & 2.000 & 2.500 & 0.000 & 2.000 & 1.167 & 1.000 & 2.000 & 1.167 \\
CSF 6 & 3.000 & 4.000 & 3.000 & 3.167 & 2.000 & 0.000 & 3.000 & 2.667 & 4.000 & 3.000 \\
CSF 7 & 3.333 & 3.000 & 2.833 & 4.000 & 3.833 & 2.000 & 0.000 & 3.000 & 3.500 & 4.000 \\
CSF 8 & 2.000 & 2.833 & 3.833 & 4.000 & 3.000 & 2.000 & 2.000 & 0.000 & 3.167 & 4.000 \\
CSF 9 & 2.500 & 3.167 & 3.667 & 3.667 & 3.000 & 1.333 & 2.000 & 3.000 & 0.000 & 3.500 \\
CSF 10 & 2.167 & 2.833 & 3.833 & 4.000 & 4.000 & 2.000 & 3.000 & 3.833 & 2.000 & 0.000 \\
\hline
\end{tabular}

Further, Equations (2) and (3) are used to transform the total direct relation matrix into a normalised direct-relation matrix. The normalised direct-relation matrix of the identified CSFs is shown in Table 5.

Table 5. Normalized direct-relation matrix (D).

\begin{tabular}{|c|c|c|c|c|c|c|c|c|c|c|}
\hline CSFs & CSF 1 & CSF 2 & CSF 3 & CSF 4 & CSF 5 & CSF 6 & CSF 7 & CSF 8 & CSF 9 & CSF 10 \\
\hline CSF 1 & 0 & 0.0781 & 0.0885 & 0.1198 & 0.0990 & 0.0938 & 0.0417 & 0.0938 & 0.1250 & 0.1146 \\
\hline CSF 2 & 0.0625 & 0 & 0.1094 & 0.0885 & 0.0677 & 0.0625 & 0.0625 & 0.1146 & 0.0625 & 0.0938 \\
\hline CSF 3 & 0.0625 & 0.0833 & 0 & 0.1250 & 0.0938 & 0.0938 & 0.0677 & 0.0938 & 0.0313 & 0.0625 \\
\hline CSF 4 & 0.0313 & 0.0625 & 0.0729 & 0 & 0.0573 & 0.0313 & 0.0625 & 0.0938 & 0.0625 & 0.0313 \\
\hline CSF 5 & 0.0625 & 0.0677 & 0.0625 & 0.0781 & 0 & 0.0625 & 0.0365 & 0.0313 & 0.0625 & 0.0365 \\
\hline CSF 6 & 0.0938 & 0.1250 & 0.0938 & 0.0990 & 0.0625 & 0 & 0.0938 & 0.0833 & 0.1250 & 0.0938 \\
\hline CSF 7 & 0.1042 & 0.0938 & 0.0885 & 0.1250 & 0.1198 & 0.0625 & 0 & 0.0938 & 0.1094 & 0.1250 \\
\hline CSF 8 & 0.0625 & 0.0885 & 0.1198 & 0.1250 & 0.0938 & 0.0625 & 0.0625 & 0 & 0.0990 & 0.1250 \\
\hline CSF 9 & 0.0781 & 0.0990 & 0.1146 & 0.1146 & 0.0938 & 0.0417 & 0.0625 & 0.0938 & 0 & 0.1094 \\
\hline CSF 10 & 0.0677 & 0.0885 & 0.1198 & 0.1250 & 0.1250 & 0.0625 & 0.0938 & 0.1198 & 0.0625 & 0 \\
\hline
\end{tabular}

After that, Equation (4) is used to transform this normalised relation matrix into a total relation matrix, as illustrated in Table 6.

Table 6. The total relation matrix $(\mathrm{T})$.

\begin{tabular}{ccccccccccc}
\hline CSFs & CSF 1 & CSF 2 & CSF 3 & CSF 4 & CSF 5 & CSF 6 & CSF 7 & CSF 8 & CSF 9 & CSF 10 \\
\hline CSF 1 & 0.2058 & 0.3329 & 0.3716 & 0.4366 & 0.3598 & 0.2795 & 0.2410 & 0.3602 & 0.3523 & 0.3592 \\
CSF 2 & 0.2372 & 0.2251 & 0.3507 & 0.3674 & 0.2980 & 0.2280 & 0.2323 & 0.3419 & 0.2658 & 0.3085 \\
CSF 3 & 0.2311 & 0.2945 & 0.2411 & 0.3867 & 0.3100 & 0.2487 & 0.2307 & 0.3146 & 0.2341 & 0.2721 \\
CSF 4 & 0.1583 & 0.2186 & 0.2465 & 0.2031 & 0.2206 & 0.1507 & 0.1810 & 0.2544 & 0.2059 & 0.1908 \\
CSF 5 & 0.1831 & 0.2202 & 0.2325 & 0.2698 & 0.1612 & 0.1761 & 0.1557 & 0.1969 & 0.2037 & 0.1898 \\
CSF 6 & 0.3011 & 0.3830 & 0.3875 & 0.4318 & 0.3395 & 0.2015 & 0.2934 & 0.3636 & 0.3623 & 0.3549 \\
CSF 7 & 0.3159 & 0.3637 & 0.3917 & 0.4649 & 0.3987 & 0.2671 & 0.2133 & 0.3798 & 0.3563 & 0.3870 \\
CSF 8 & 0.2595 & 0.3347 & 0.3910 & 0.4339 & 0.3501 & 0.2485 & 0.2546 & 0.2689 & 0.3216 & 0.3608 \\
CSF 9 & 0.2655 & 0.3339 & 0.3766 & 0.4139 & 0.3410 & 0.2245 & 0.2466 & 0.3451 & 0.2234 & 0.3395 \\
CSF 10 & 0.2691 & 0.3401 & 0.3961 & 0.4410 & 0.3824 & 0.2537 & 0.2846 & 0.3807 & 0.2977 & 0.2547 \\
\hline
\end{tabular}

The causal parameters are calculated using the total relation matrix value. The total relation matrix's row-wise summation (using Equation (5)) is indicated as $R_{i}$, while the total relation matrix's column-wise summation (using Equation (6)) is shown as $C_{i}$. Equations (7) and (8) are used to calculate the prominence $\left(P_{i}=R_{i}+C_{i}\right)$ and net effect $\left(E_{i}=R_{i}+C_{i}\right)$ from $R_{i}$ and $C_{i}$. Table 7 shows the causal parameters.

When the value of $\left(E_{i}=R_{i}-C_{i}\right)$ is positive, the CSFs are considered influential; otherwise, they are considered influenced. Based on the value of the $\left(E_{i}\right)$, the CSFs are divided into a cause-and-effect group. The prominence vector $\left(P_{i}\right)$ is plotted on the horizontal axis, and the net effect vector $\left(E_{i}\right)$ is plotted on the vertical axis. The causal relationship 
diagram is developed and shown in Figure 2. This cause-and-effect diagram not only aids in determining the influence of one CSF on another, but also helps in filtering out certain minor effects from the causal effect diagram.

Table 7. Cause and effect of CSFs to adopt logistics 4.0.

\begin{tabular}{cccccc}
\hline CSFs & R & C & R + C & R - C & Cause/Effect \\
\hline CSF 1 & 3.2989 & 2.4267 & 5.7257 & 0.8722 & Cause \\
CSF 2 & 2.8548 & 3.0467 & 5.9015 & -0.1919 & Effect \\
CSF 3 & 2.7636 & 3.3853 & 6.1489 & -0.6217 & Effect \\
CSF 4 & 2.0299 & 3.8491 & 5.8790 & -1.8192 & Effect \\
CSF 5 & 1.9889 & 3.1611 & 5.1500 & -1.1722 & Effect \\
CSF 6 & 3.4187 & 2.2785 & 5.6972 & 1.1402 & Cause \\
CSF 7 & 3.5384 & 2.3332 & 5.8716 & 1.2052 & Cause \\
CSF 8 & 3.2238 & 3.2060 & 6.4299 & 0.0178 & Cause \\
CSF 9 & 3.1100 & 2.8231 & 5.9331 & 0.2869 & Cause \\
CSF 10 & 3.3001 & 3.0173 & 6.3173 & 0.2828 & Cause \\
\hline
\end{tabular}

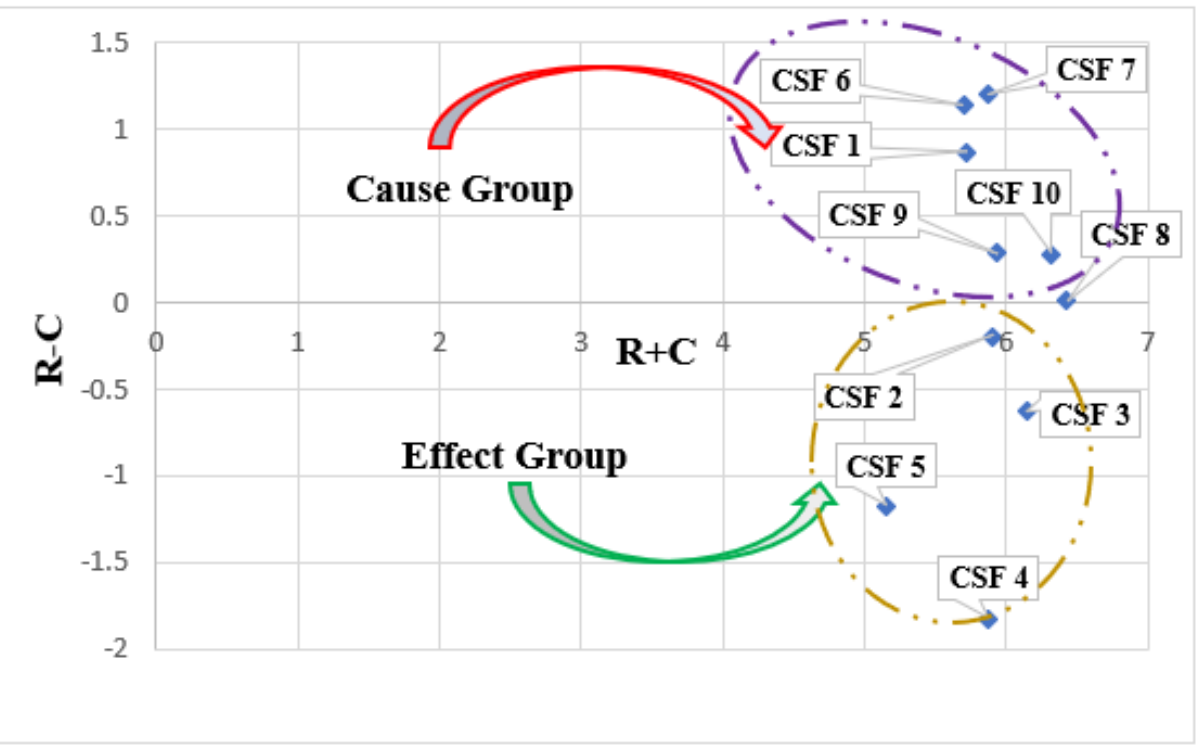

Figure 2. Causal map for CSFs of logistics 4.0 adoption.

Further, these CSFs are ranked based on the value of prominence score ' $R+C^{\prime}$ and effect score ' $R-C^{\prime}$. The ranking of these factors is shown in Table 8 .

Table 8. Ranking of the CSFs towards the adoption of logistics 4.0.

\begin{tabular}{ccccc}
\hline CSFs & R + C & Rank & R $-\mathbf{C}$ & Rank \\
\hline CSF 1 & 5.7257 & 8 & 0.8722 & 3 \\
CSF 2 & 5.9015 & 5 & -0.1919 & 7 \\
CSF 3 & 6.1489 & 3 & -0.6217 & 8 \\
CSF 4 & 5.879 & 6 & -1.8192 & 10 \\
CSF 5 & 5.15 & 10 & -1.1722 & 9 \\
CSF 6 & 5.6972 & 9 & 1.1402 & 2 \\
CSF 7 & 5.8716 & 7 & 1.2052 & 1 \\
CSF 8 & 6.4299 & 1 & 0.0178 & 6 \\
CSF 9 & 5.9331 & 4 & 0.2869 & 4 \\
CSF 10 & 6.3173 & 2 & 0.2828 & 5 \\
\hline
\end{tabular}

\section{Discussion}

DEMATEL analysis suggested a ranking of each CSFs importance, as well as a classification of the CSFs into two groups: "influential" and "influenced". The influential group 
CSFs has significant research implications since these factors have a big impact on the aim of logistics 4.0 adoption. It should be mentioned that improving one or two CSFs would not enhance the total system because the CSFs are interconnected. To make effective decisions, the CSFs must be divided into cause-and-effect groups. First, the influential group CSFs are enhanced, and then the effect group CSFs are improved. The next part deals with cause-and-effect groups in more depth.

\subsection{Influencing Factors}

The DEMATEL analysis reveals that six CSFs are fallen into influencing groups based on the value of $E_{i}\left(R_{i}-C_{i}>0\right)$. The importance order of these CSFs is: 'top management commitment and support' $>$ 'aligning the initiatives of logistic 4.0 with organizational strategy' > 'technological infrastructure' > 'willingness to invest in logistics $4.0^{\prime}$ ' > 'training and education $>$ 'research environment'. It should be noted that improvements in the influencing factors result in advancements in the other influenced factors. As a result, we must initially concentrate on these factors.

The most influencing is 'top management commitment and support' as logistics 4.0 demands several smart technologies, integration, and coordination. The organisations need to provide support in terms of financial and technological aspects to effectively adopt Industry 4.0. The second most influencing factor is the 'aligning the initiatives of logistics 4.0 with organizational strategy' that motivates the management to develop the strategies and planning in favour of logistics 4.0 adoption. This also helps to take several logistics 4.0 initiatives such as the adoption of big data analytics, IoT, CPS, and traceability. Further, the next influencing CSFs is 'technological infrastructure' such as real-time condition monitoring, high-speed data sharing technologies, virtual interface and other smart technologies that are essential to adopt logistics 4.0. This technological infrastructure influences some other factors such as developing the smart work culture and analytical capabilities.

Further, 'willingness to invest in logistics 4.0 ' is also an influencing factor that is seeking the stakeholder's attention. Logistic 4.0 demands high investment and this investment comes from the stakeholder of logistics 4.0. Therefore, willingness to pay is vital for the adoption of logistics 4.0 for obtaining the fruitful result. As logistics 4.0 is an emerging concept and requires a new set of skills and responsibilities, to facilitate this, 'training and education' became a significant factor. The training could be provided through seminars and workshops to logistics working for personnel. This might help to develop a smart culture and enhance knowledge transfer. The last influencing factor among the identified factor is the 'research environment' to develop the process and technologies that support the logistics 4.0 adoption. To create a research environment within the organisation, top management is required to promote the research through several monetary and nonmonetary incentives. The research and development help in knowledge transfer, smart work culture and analytical capabilities development.

\subsection{Influenced Factors}

Four factors belong to the influenced group that is affected by the influencing factors. As the influenced group factor has a dependent connection with the influencing group factors, these factors may be enhanced as the cause group CSFs improve. The importance order of the influenced group is: 'development of analytical capabilities' > 'smart work environment' > 'knowledge transfer' > 'trust and collaboration'. The development of the analytical capabilities is influenced by several factors such as top management commitment, research environment, and technological infrastructure. The next most influenced smart work environment could be created by the top management support and commitment. Further, knowledge transfer is also influenced by other influencing factors such as training and research culture. Trust and collaboration have also come in the category of influence factors that are influenced by top management commitment. 


\subsection{Ranking of Factors}

The prominence $P_{i}(=\mathrm{R}+\mathrm{C})$ represents the 'total cause and effect'. The higher prominence score signifies the greater importance of factors ' $i$ ' in terms of overall relationships with other factors. The influence $E_{i}(=\mathrm{R}-\mathrm{C})$ represents the 'net impact or cause' of CSFs. The ranking based on the value of $P_{i}$ demonstrates prioritisation based on the overall cause and effect (important), whereas the ranking based on the value of $E_{i}$ demonstrates the influential order of the factors. Based on the value of $P_{i}$, the importance order of the CSFs is: 'research environment' > 'training and education' > 'knowledge transfer' $>$ 'willingness to invest in logistics $4.0^{\prime}>$ 'trust and collaboration' > 'development of analytical capabilities' > 'top management commitment and support' > 'technological infrastructure' > 'aligning the initiatives of logistics 4.0 with organizational strategy' > 'smart work environment'. The most important factors are 'creating the research environment' and 'training and education'.

Based on the value of $E_{i}$, the importance order is 'top management commitment and support' > 'aligning the initiatives of logistics 4.0 with organizational strategy' > 'technological infrastructure' $>$ 'willingness to invest in logistics 4.0' > 'training and education' > 'research environment' > 'trust and collaboration' > 'knowledge transfer' > 'smart work environment' > 'development of analytical capabilities'. The top influential factors among the identified CSFs are the 'top management commitment and support' and 'aligning the initiatives of logistics 4.0 with organizational strategy'. These factors are essential for the adoption of logistics 4.0.

\section{Managerial Implications}

Logistics 4.0 is an emerging concept, and its adoption is a challenging task. Therefore, the organisations are looking for a decision support system that could help them in the decision making towards the adoption of logistics 4.0. Further, the organisations are also exploring the way to implement logistics 4.0. In this regard, this study is helpful by providing a list of CSFs that are significant for the adoption of logistics 4.0. Through the assessment of these factors, organisations are in well-informed position regarding the adoption of logistics 4.0. Further, the result of this research is also beneficial for the managers to focus only on influencing factors as they could not emphasise each factor simultaneously. Primarily, the managers should focus on the influencing factors and later influenced factors. In order words, top management commitment and support should be provided in terms of monetary and non-monetary to implement logistics 4.0. The top management might be motivated by providing the impact of logistics 4.0 on their business performance. Apart from this, a technological infrastructure also needs to be developed in order to effectively adopt logistics 4.0 , and this could develop with the publicprivate partnership. Therefore, the manager should be ready to invest in developing the technological infrastructure. The other cause factors 'willingness to invest in logistics $4.0^{\prime}$, 'training and education' and 'research environment' need to address on a priority basis. The causal map also helps the policy planner to formulate the strategies to implement these factors by understanding the causal relationship.

\section{Conclusions}

In the current business environment, consumer preferences are continuously changing. To fulfil these requirements, several supply chain solutions are purposed. One important aspect of the supply chain is the logistics that are receiving much attention from the supply chain managers, as it creates more value for the customer by providing more transparency, reduced lead time, traceability, condition monitoring, etc., through the adoption of logistics 4.0. This study revolves around the adoption of logistics 4.0 through the focus on CSFs. Initially, the CSFs of adoption of logistics 4.0 are identified through the integrated approach of literature survey and experts' input in the domain of logistics. After the finalisation of the CSFs, a causal relationship is developed through the DEMATEL method. The analysis also categorised the CSFs into the cause-and-effect groups. The finding shows that six factors belong to the cause group and four factors belong to the effect group. The 'top management 
commitment and support', 'aligning the initiatives of logistics 4.0 with organizational strategy' and 'technological infrastructure' are the most influential CSFs. It should be noted that improvements in the influencing factors result in advancements in the other influenced factors. As a result, managers, policymakers, and professionals should focus on these factors on an urgent basis to adapt logistics 4.0. Further, this study also prioritises these identified CSFs based on the prominence and effect score.

Similar to the other studies, this study also holds certain limitations. The first limitation is that there is a possibility to overlook some CSFs as a very limited study is available on logistics 4.0. Secondly, the finalisation of the identified CSFs is based on the experts' input, and they could be biased towards their managerial position, geography, and their organisation. Thirdly, the causal relationship is developed through the DEMATEL method that is an expert-based tool.

These limitations could be relieved in future studies. In the upcoming studies, a systematic literature review with a greater number of articles could be conducted for the identification of the CSFs. These factors could be validated through the case studies that will help in generalising the findings of this study. Further, this study was also conducted by taking a large sample size instead of six experts. In order to develop the causal relationship, other modelling tools such as structural equation modelling, system dynamics and modified TISM could be used. These CSFs could also prioritise for other useful insights using the BWM, AHP or ANP.

Author Contributions: S.K. and A.H. conceived the idea and administrated the project. S.K. and R.S. surveyed the literature and find CSFs. S.K. contributed to the analysis, S.K., R.S. and J.D. wrote the paper, and S.S.A. edited the original draft. All authors have read and agreed to the published version of the manuscript.

Funding: This research received no external funding.

Institutional Review Board Statement: Not applicable.

Informed Consent Statement: Not applicable.

Data Availability Statement: Not applicable.

Conflicts of Interest: The authors declare no conflict of interest.

\section{References}

1. Sony, M.; Antony, J.; Mc Dermott, O.; Garza-Reyes, J.A. An empirical examination of benefits, challenges, and critical success factors of industry 4.0 in manufacturing and service sector. Technol. Soc. 2021, 67, 101754. [CrossRef]

2. Masood, T.; Sonntag, P. Industry 4.0: Adoption challenges and benefits for SMEs. Comput. Ind. 2020, 121, 103261. [CrossRef]

3. Culot, G.; Nassimbeni, G.; Orzes, G.; Sartor, M. Behind the definition of Industry 4.0: Analysis and open questions. Int. J. Prod. Econ. 2020, 226, 107617. [CrossRef]

4. Yin, Y.; Stecke, K.E.; Li, D. The evolution of production systems from Industry 2.0 through Industry 4.0. Int. J. Prod. Res. 2017, 56, 848-861. [CrossRef]

5. Yüksel, H. An empirical evaluation of industry 4.0 applications of companies in Turkey: The case of a developing country. Technol. Soc. 2020, 63, 101364. [CrossRef]

6. Liao, Y.; Deschamps, F.; Loures, E.d.F.R.; Ramos, L.F.P. Past, present and future of Industry 4.0-A systematic literature review and research agenda proposal. Int. J. Prod. Res. 2017, 55, 3609-3629. [CrossRef]

7. Khan, S.; Singh, R. Kirti Critical Factors for Blockchain Technology Implementation: A Supply Chain Perspective. J. Ind. Integr. Manag. 2021, 2150011. [CrossRef]

8. Javaid, M.; Haleem, A.; Singh, R.P.; Rab, S.; Suman, R.; Khan, S. Exploring relationships between Lean 4.0 and manufacturing industry. Ind. Robot. Int. J. Robot. Res. Appl. 2021. [CrossRef]

9. Jeschke, S. Quo Vadis Logistik 4.0. 2016. Available online: www.ima-zlw-ifu.rwth-aach-en.de/fileadmin/user_upload/ INSTITUTSCLUSTER/Publikation_Medien/Vortraege/download//Quo_vadis_Logistik4.0_17March2016.pdf (accessed on 6 January 2022).

10. Timm, J.; Lorig, F. Logistics 4.0-A Challenge for Simulation. In Proceedings of the 2015 Winter Simulation Conference, Huntington Beach, CA, USA, 6-9 December 2015; Yilmaz, L., Chan, W.K.V., Moon, I., Roeder, T.M.K., Macal, C., Rossetti, D., Eds.; IEEE Press: Piscataway, NJ, USA, 2015; pp. 3118-3119. 
11. Ali, S.S.; Poksoy, T.; Torğul, B.; Kaur, R. Reverse logistics optimization of an industrial air conditioner manufacturing company for designing sustainable supply chain: A fuzzy hybrid multi-criteria decision-making approach. Wirel. Netw. 2020, 26, 5759-5782. [CrossRef]

12. Wang, K. Logistics 4.0 Solution-New Challenges and Opportunities. In Proceedings of the 6th International Workshop of Advanced Manufacturing and Automation, London, UK, 27-28 October 2016. [CrossRef]

13. Raj, A.; Sah, B. Analyzing critical success factors for implementation of drones in the logistics sector using grey-DEMATEL based approach. Comput. Ind. Eng. 2019, 138, 106118. [CrossRef]

14. Paksoy, T.; Kochan, C.D.; Ali, S.S. Logistics 4.0: Digital Transformation of Supply Chain Management; CRC Press: Boca Raton, FL, USA, 2020; pp. 122-134.

15. Ghadge, A.; Kara, M.E.; Moradlou, H.; Goswami, M. The impact of Industry 4.0 implementation on supply chains. J. Manuf. Technol. Manag. 2020, 31, 669-686. [CrossRef]

16. Choudhury, A.; Behl, A.; Sheorey, P.A.; Pal, A. Digital supply chain to unlock new agility: A TISM approach. Benchmarking Int. J. 2021. [CrossRef]

17. Atzeni, G.; Vignali, G.; Tebaldi, L.; Bottani, E. A bibliometric analysis on collaborative robots in Logistics 4.0 environments. Procedia Comput. Sci. 2021, 180, 686-695. [CrossRef]

18. Markov, K.; Vitliemov, P. Logistics 4.0 and supply chain 4.0 in the automotive industry. IOP Conf. Ser. Mater. Sci. Eng. 2020, 878 , 012047. [CrossRef]

19. Ali, S.S.; Kaur, R.; Goyal, K. Gazelle Infotech- Optimizing Humanitarian Supply Chain for Disaster Management. Emerald Emerg. Mark. Case Stud. 2020, 10. [CrossRef]

20. Winkelhaus, S.; Grosse, E.H. Logistics 4.0: A systematic review towards a new logistics system. Int. J. Prod. Res. 2019, 58, 18-43. [CrossRef]

21. Kucukaltan, B.; Saatcioglu, O.Y.; Irani, Z.; Tuna, O. Gaining strategic insights into Logistics 4.0: Expectations and impacts*. Prod. Plan. Control 2020, 33, 1-17. [CrossRef]

22. Di Nardo, M.; Clericuzio, M.; Murino, T.; Sepe, C. An Economic Order Quantity Stochastic Dynamic Optimization Model in a Logistic 4.0 Environment. Sustainability 2020, 12, 4075. [CrossRef]

23. Nantee, N.; Sureeyatanapas, P. The impact of Logistics 4.0 on corporate sustainability: A performance assessment of automated warehouse operations. Benchmarking Int. J. 2021, 28, 2865-2895. [CrossRef]

24. Torbacki, W.; Kijewska, K. Identifying Key Performance Indicators to be used in Logistics 4.0 and Industry 4.0 for the needs of sustainable municipal logistics by means of the DEMATEL method. Transp. Res. Procedia 2019, 39, 534-543. [CrossRef]

25. Kodym, O.; Kubáč, L.; Kavka, L. Risks associated with Logistics 4.0 and their minimization using Blockchain. Open Eng. 2020, 10, 74-85. [CrossRef]

26. Bag, S.; Gupta, S.; Luo, Z. Examining the role of logistics 4.0 enabled dynamic capabilities on firm performance. Int. J. Logist. Manag. 2020, 31, 607-628. [CrossRef]

27. Wagner, T.A.; Herrmann, C.; Thiede, S. Industry 4.0 Impacts on Lean Production Systems. Procedia CIRP 2017, 63, 125-131. [CrossRef]

28. Mayr, A.; Weigelt, M.; Kuhi, A.; Grimm, S.; Erll, A.; Potzel, M.; Franke, J. Lean 4.0-A conceptual conjunction of Lean management and Industry4.0. Procedia CIRP 2018, 72, 622-628. [CrossRef]

29. Ali, S.S.; Kaur, R.; Gupta, H.; Ahmad, Z.; Elnaggar, G. Determinants of an Organization's Readiness for Drone Technologies Adoption. IEEE Trans. Eng. Manag. 2021. [CrossRef]

30. Beier, G.; Ullrich, A.; Niehoff, S.; Reißig, M.; Habich, M. Industry 4.0: How it is defined from a sociotechnical perspective and how much sustainability it includes-A literature review. J. Clean. Prod. 2020, 259, 120856. [CrossRef]

31. Rosin, F.; Forget, P.; Lamouri, S.; Pellerin, R. Impacts of Industry 4.0 technologies on Lean principles. Int. J. Prod. Res. 2019, 58, 1644-1661. [CrossRef]

32. Götz, M.; Jankowska, B. Clusters and Industry 4.0-do they fit together? Eur. Plan. Stud. 2017, 25, 1633-1653. [CrossRef]

33. Fonseca, L.M. Industry 4.0 and the digital society: Concepts, dimensions and envisioned benefits. Proc. Int. Conf. Bus. Excell. 2018, 12, 386-397. [CrossRef]

34. D'Orazio, L.; Messina, R.; Schiraldi, M.M. Industry 4.0 and World Class Manufacturing Integration: 100 Technologies for a WCM-I4.0 Matrix. Appl. Sci. 2020, 10, 4942. [CrossRef]

35. Qin, J.; Liu Ying Grosvenor, R. A categorical framework of manufacturing for Industry4.0 and beyond. Procedia CIRP 2016, 52, 173-178. [CrossRef]

36. Kagermann, H.; Wahlster, W.; Helbig, J. Recommendation for implementing the strategic initiative INDUSTRIE 4.0-Securing the Future of German Manufacturing Industry, Final report of the Industrie 4.0 Working Group. In Acatech-National Academy of Science and Engineering; Forschungsunion: Munchen, Germany, 2013.

37. Khan, S.; Haleem, A.; Khan, M.I.; Abidi, M.H.; Al-Ahmari, A. Implementing Traceability Systems in Specific Supply Chain Management (SCM) through Critical Success Factors (CSFs). Sustainability 2018, 10, 204. [CrossRef]

38. Yadav, S.; Luthra, S.; Garg, D. Internet of things (IoT) based coordination system in Agri-food supply chain: Development of an efficient framework using DEMATEL-ISM. Oper. Manag. Res. 2020, 1-27. [CrossRef]

39. Khan, M.I.; Khan, S.; Khan, U.; Haleem, A. Modeling the Big Data challenges in context of smart cities-An integrated fuzzy ISM-DEMATEL approach. Int. J. Build. Pathol. Adapt. 2021. [CrossRef] 
40. Sufiyan, M.; Haleem, A.; Khan, S.; Khan, M.I. Evaluating food supply chain performance using hybrid fuzzy MCDM technique. Sustain. Prod. Consum. 2019, 20, 40-57. [CrossRef]

41. Khan, S.; Khan, M.I.; Haleem, A. Towards Effective Management of Cold Chain: A DEMATEL Approach. IOP Conf. Ser. Mater. Sci. Eng. 2018, 404, 012019. [CrossRef]

42. Haleem, A.; Khan, S.; Khan, M.I. Traceability implementation in food supply chain: A grey-DEMATEL approach. Inf. Process. Agric. 2019, 6, 335-348. [CrossRef]

43. Khan, S.; Haleem AKhan, M. Risk management in Halal supply chain: An integrated fuzzy Delphi and DE-MATEL approach. J Model. Manag. 2020, 16, 172-214. [CrossRef]

44. Silva, N.; Barros, J.; Santos, M.Y.; Costa, C.; Cortez, P.; Carvalho, M.S.; Gonçalves, J.N.C. Advancing Logistics 4.0 with the Implementation of a Big Data Warehouse: A Demonstration Case for the Automotive Industry. Electronics 2021, $10,2221$. [CrossRef]

45. Cimini, C.; Lagorio, A.; Pirola, F.; Pinto, R. Exploring human factors in Logistics 4.0: Empirical evidence from a case study. IFAC-PapersOnLine 2019, 52, 2183-2188. [CrossRef]

46. Ali, S.S.; Deka, S.; Jaswal, M.; Ahmad, Z.; AlSulami, H. Feasibility of drone integration as last mile delivery. Emerald Emerg. Mark. Case Stud. 2019, 9, 1-17. [CrossRef]

47. Joshi, S.; Sharma, M. Digital technologies (DT) adoption in agri-food supply chains amidst COVID-19: An approach towards food security concerns in developing countries. J. Glob. Oper. Strat. Sourc. 2021. [CrossRef]

48. Ali, S.S.; Kaur, R.; Ersöz, F.; Lotero, L.; Weber, G.W. Evaluation of the effectiveness of green practices in Indian manufacturing sector using CHAID analysis. J. Remanufacturing 2019, 9, 3-27. [CrossRef]

49. Jagtap, S.; Bader, F.; Garcia-Garcia, G.; Trollman, H.; Fadiji, T.; Salonitis, K. Food Logistics 4.0: Opportunities and Challenges. Logistics 2020, 5, 2. [CrossRef]

50. Rejeb, A.; Keogh, J.G.; Zailani, S.; Treiblmaier, H.; Rejeb, K. Blockchain Technology in the Food Industry: A Review of Potentials, Challenges and Future Research Directions. Logistics 2020, 4, 27. [CrossRef]

51. Facchini, F.; Oleśków-Szłapka, J.; Ranieri, L.; Urbinati, A. A Maturity Model for Logistics 4.0: An Empirical Analysis and a Roadmap for Future Research. Sustainability 2019, 12, 86. [CrossRef]

52. Rahman, M.; Kamal, M.M.; Aydin, E.; Haque, A.U. Impact of Industry 4.0 drivers on the performance of the service sector: Comparative study of cargo logistic firms in developed and developing regions. Prod. Plan. Control 2020, 33, 1-16. [CrossRef]

53. Kumar, A.; Choudhary, S.; Garza-Reyes, J.A.; Kumar, V.; Khan, S.A.R.; Mishra, N. Analysis of critical success factors for implementing Industry 4.0 integrated circular supply chain-moving towards sustainable operations. Prod. Plan. Control 2021, 1-15. [CrossRef]

54. Haleem, A.; Khan, S.; Pundir, H.; Jain, A.; Upadhyay, P.; Khan, M.I. Investigating Barriers Toward the Implementation of Circular Economy: A Fuzzy CRITIC Approach. J. Ind. Integr. Manag. 2020, 6, 107-139. [CrossRef]

55. Ozkan-Ozen, Y.D.; Kazancoglu, Y.; Kumar Mangla, S. Synchronized barriers for circular supply chains in industry $3.5 /$ industry 4.0 transition for sustainable resource management. Resour. Conserv. Recycl. 2020, 161, 104986. [CrossRef]

56. Wang, B.; Ha-Brookshire, J.E. Exploration of Digital Competency Requirements within the Fashion Supply Chain with an Anticipation of Industry 4.0. Int. J. Fash. Des. Technol. Educ. 2018, 11, 333-342. [CrossRef]

57. Hou, T.; Cheng, B.; Wang, R.; Xue, W.; Chaudhry, P.E. Developing Industry 4.0 with systems perspectives. Syst. Res. Behav. Sci. 2020, 37, 741-748. [CrossRef]

58. Lee, H.; Tzeng, G.; Yeih, W.; Wang, Y.; Yang, S. Revised DEMATEL: Resolving the Infeasibility of DE-MATEL. Appl. Math. Model. 2013, 37, 6746-6757. [CrossRef]

59. Xia, X.; Govindan, K.; Zhu, Q. Analyzing internal barriers for automotive parts remanufacturers in China using grey-DEMATEL approach. J. Clean. Prod. 2015, 87, 811-825. [CrossRef]

60. Zhu, Q.; Sarkis, J.; Lai, K. Supply chain-based barriers for truck-engine remanufacturing in China. Transp. Res. Part E Logist. Transp. Rev. 2014, 68, 103-117. [CrossRef]

61. Govindan, K.; Khodaverdi, R.; Vafadarnikjoo, A. A grey DEMATEL approach to develop third-party logistics provider selection criteria. Ind. Manag. Data Syst. 2016, 116, 690-722. [CrossRef]

62. Luthra, S.; Govindan, K.; Mangla, S.K. Structural model for sustainable consumption and production adoption-A greyDEMATEL based approach. Resour. Conserv. Recycl. 2017, 125, 198-207. [CrossRef]

63. Khan, S.; Haleem, A. Strategies to Implement Circular Economy Practices: A Fuzzy DEMATEL. Approach. J. Ind. Integr. Manag. 2020, 5, 253-269. [CrossRef]

64. Bhatia, M.S.; Srivastava, R.K. Analysis of external barriers to remanufacturing using grey-DEMATEL approach: An Indian perspective. Resour. Conserv. Recycl. 2018, 136, 79-87. [CrossRef] 